\title{
GCU
}

Glasgow Caledonian

University

University for the Common Good

\section{Evaluation of Precipitation Rate Impacts on Overhead Transmission Line Ampacity}

Abdael Baset, Abdallah; Farrag, Mohamed Emad A.; Farokhi, Shahab

Published in:

2019 54th International Universities Power Engineering Conference (UPEC)

DOI:

10.1109/UPEC.2019.8893644

Publication date:

2019

Document Version

Author accepted manuscript

Link to publication in ResearchOnline

Citation for published version (Harvard):

Abdael Baset, A, Farrag, MEA \& Farokhi, S 2019, Evaluation of Precipitation Rate Impacts on Overhead Transmission Line Ampacity. in 2019 54th International Universities Power Engineering Conference (UPEC). IEEE, pp. 1-5, 2019 54th International Universities Power Engineering Conference (UPEC), Bucharest, Romania, 3/11/19. https://doi.org/10.1109/UPEC.2019.8893644

\section{General rights}

Copyright and moral rights for the publications made accessible in the public portal are retained by the authors and/or other copyright owners and it is a condition of accessing publications that users recognise and abide by the legal requirements associated with these rights.

Take down policy

If you believe that this document breaches copyright please view our takedown policy at https://edshare.gcu.ac.uk/id/eprint/5179 for details of how to contact us. 


\section{Evaluation of Precipitation Impacts on Overhead Transmission Line Ampacity}

\author{
Abdallah Abdaelbaset \\ Glasgow Caledonian University, \\ Abdallah.Baset@gcu.ac.uk
}

\author{
Mohamed Emad Farrag \\ Glasgow Caledonian University, \\ Mohamed.Farrag@gcu.ac.uk
}

\author{
Shahab Farokhi \\ Glasgow Caledonian University, \\ shahab.farokhi@gcu.ac.uk
}

\begin{abstract}
The worldwide fast pace at which wind power generation technology and its drive train is growing has increased the demand for wind farm connection into the power grid. The UK target of increasing wind energy contribution coupled with the excellent wind profile has led to growing demand for distribution and transmission connection points. The main obstacle hindering large scale of integration of the wind energy is the thermal capacity limits of the existing transmission lines infra structure. Thermal capacity computation techniques are based on heat balance equation stipulated in IEEE 738. This paper analyses the heat balance equation and proposes the addition of new variable to the set of heat balance equations, discusses the economic aspects of dynamic line ratings. The main objective of this paper is to mathematically integrate the effect of precipitation rate into the heat balance equation, based on empirical study conducted.
\end{abstract}

Index Terms - Ampacity of bare power lines, dynamic ratings, ruling span of transmission line, temperature overshoot effect and thermal time constant.

\section{INTRODUCTION}

Transmission lines are thermally limited in the ampacity they can safely carry by their dimensions [1]. In an energised power line and under thermal steady state conditions also known as thermal equilibrium [2], the sum of heat loss will aim to equalize that of heat gain.

Existing computation techniques used to compute the power lines ampacity assume static and worst case scenario weather parameters [3] [4]. Ampacity computation is conducted for three main purposes.

- Operational planning - short term planning $<4$ hours

- Operational planning - Long term planning $>6$ month

- Construction planning - Long term planning $>1$ year + Historically transmission network was constructed around thermal generation base load power plants and very predictable power demand, this high degree of predictability discouraged network operators from significant investments in enhancing thermal ratings of their infrastructure and consider technologies like dynamic line ratings. Some recent papers like [5] [6] outlined the conservative nature of standard thermal computation frameworks like IEEE 738 and P27. The frequency of occurrence of seasonal weather parameters stipulated in P27 standard was examined closely by [7] who stated that actual results vary $99 \%$ of the time leading to significant margins of errors in ampacity. The standard stipulated taking $2^{\circ} \mathrm{C}$ Winter, $9^{\circ} \mathrm{C}$ Autumn and $20^{\circ} \mathrm{C}$ summer as base season parameters.

978-1-7281-3349-2/19/\$31.00 @2019 IEEE
The rapid change of United Kingdom networks topology since the last decade specifically the growth in renewable energy generation plants and the regulatory policies encouraging the transition to

electric vehicles made accurate prediction of future capacity requirements very difficult. This paper will focus on solving problem statement number 1 , short term planning $<4$ hours timescales because through solving short term planning problems a much-needed level of flexibility to the carrying capacity of the overhead line network will be added. This allows time for data supporting and improving our understanding of thermal behaviour of power lines to be collated and compiled, aiding slower and more efficient transition to the new era of highly efficient wind generation and through the transformation to electrical vehicles. The ampacity computation techniques often disregard cooling effects of significant weather events such as of falling rain on conductors, this leads to a reduction in the available margins in transfer capability of the system. Average annual precipitation in Scotland is one of the highest in Europe $1627.9 \mathrm{~mm}$ [8] compared with $1129 \mathrm{~mm}$ annual average in the UK and $900 \mathrm{~mm}$ in the EEA area [9] [10].

Solar and electrical heat gain $Q_{S}$ and $Q_{E M}$ do not change significantly with rain, however the conductor heat losses parameters specifically convective heat loss reacts differently during rainy days. Rain droplets reduce viscosity of air and increase air mass of air [11]. Impact of rain was touched on by the work done by pioneers like Murray Davies, whose work influenced the formation of IEEE 738, Murray found that convective cooling increases by $50 \%$ when conductor is wet [12]. Nevertheless, this finding was not reflected in the computation framework of IEEE 738, which treated any nonconvective and non-radiant heat loss as possessing a transient characteristic. Convective heat loss constitutes the larger share of heat loss in transmission lines, factors affecting convective heat loss are wind speed, rain and to a lesser extent ambient temperature. Many analytical tools were developed by researchers around the world such as finite element models (FEM) to compute convectional heat loss of transmission lines, main limitation of the (FEM) as summarised by [13] is the poor real time calculation capacity.

\section{IEEE 738 FRAMEWORK}

$Q_{C}+Q_{R}=Q_{S}+Q_{E M}$

(1)

Where $Q_{C}$ is the Convective heat loss 
$Q_{C}=N_{U} * \lambda * \pi *\left(\boldsymbol{T}-T_{a}\right)$

(2)

And;

$N_{U}$ low $=0.32+0.43 * R e^{0.52}$ low wind speeds

(3)

$N_{U} h i=0.24^{*} \quad R e^{0.6}$ high wind speeds

(4)

$R_{e}=v D \gamma / \eta$

(5)

Where

$v$-Wind speed

$D$ - Diameter of the cable

$\gamma$-Specific mass of air

$\eta$ - Dynamic viscosity of air

$\lambda$ - Thermal conductivity of air

$N_{U}-$ Nusselt number

$T$ - Conductor temperature

$T_{a}$ - Ambient temperature

$Q_{R}$ is the radiant heat loss

$Q_{R}=K_{s} * K_{e} * D * \pi *\left(T^{4}-T_{a}{ }^{4}\right)$

(6)

Where,

$K_{s}$ - Stefan-Boltzmann constant.

$K_{e}-$ Emission coefficient.

$D$ - Diameter of the cable.

$T$ - Conductor temperature

$T_{a}$ - Ambient temperature.

$Q_{S}$ is the Solar heat gain

$Q_{S}=D * K_{a} * Q_{S H}$

(7)

Where,

$D$ - Diameter of the conductor

$K_{a}$ - Absorption coefficient

$Q_{S H}-$ Standard solar radiation

$Q_{E M}$ Electrical heat losses

$Q_{E M}=\mathrm{I}_{\mathrm{rms}}^{2} * \alpha \mathrm{R}_{\mathrm{T}}(8)$

$R_{T}=\mathrm{R}_{20}(1+\alpha(\mathrm{T}-20))$

(9)

Where,

$I_{r m s}-$ RMS current flowing in a single conductor

$R_{20}$ - AC Resistance of the conductor at room temperature

$R_{T}$ - AC Resistance in the conductor, at temperature $T$

$\alpha R$ - Temperature coefficient of resistance, in $1^{\circ} \mathrm{C}$

$T$ - Temperature of the conductor

\section{CONDUCTIVE HEAT LOSS}

There is a third thermal cooling parameter that captures the effect of rain on thermal behaviour of a hot power conductor; i.e. conductive heat loss, it is a function of thermal gradient between air and conductor's cross-sectional area and can be computed as...

$Q=\frac{K A\left(T_{a}-T_{C}\right)}{D}$

Where,

$Q$ - Conductive heat loss

$K$-Conductivity of Air @ 300 kelvin $/ 26.85^{\circ} \mathrm{C}$ is 0.02614

$A$ - Cross sectional area

$D$-Conductor thickness

$T_{a}$ - Ambient temperature

$T_{c}$ - Conductor temperature

Conductive heat loss increases with increased conductor temperature, unlike convective heat loss it is less sensitive to changes in wind speed but more sensitive to ambient and conductor temperature changes, it increases with reduced ambient temperature and increases with increasing conductor surface temperature. Tables 1 and 2 outline a comparative computation study made to compare between Ampacity on a wet $\&$ dry day [Note: this study did not take ambient air temperature drop and increase in wind speed that normally accompanies rain into consideration]

T able 1- Ampacity computation using IEEE 738 standard framework model

\begin{tabular}{|c|c|c|}
\hline \multicolumn{2}{|c|}{ No adjustment - IEEE 738 model } \\
\hline Surface temperature of conductor & Ampacity & $\begin{array}{c}\text { Conductive heat } \\
\text { loss W/m }\end{array}$ \\
\hline $40^{\circ} \mathrm{C}$ & $1525 \mathrm{Amps}$ & 0 \\
\hline $50^{\circ} \mathrm{C}$ & $1767 \mathrm{Amps}$ & 0 \\
\hline $60^{\circ} \mathrm{C}$ & $1971 \mathrm{Amps}$ & 0 \\
\hline $70^{\circ} \mathrm{C}$ & $2149 \mathrm{Amps}$ & 0 \\
\hline $80^{\circ} \mathrm{C}$ & $2308 \mathrm{Amps}$ & \\
\hline & & \\
\hline
\end{tabular}

Table 2 - Ampacity computed with conductive cooling added to the equation

\begin{tabular}{|c|c|c|c|}
\hline \multicolumn{4}{|c|}{ Adjusted for rain- Proposed model } \\
\hline $\begin{array}{c}\text { Surface temperature } \\
\text { of conductor }\end{array}$ & Ampacity & $\begin{array}{c}\text { Conductive heat } \\
\text { loss W/m } \\
\text { Increases with } \\
\text { increasing } \\
\text { surface } \\
\text { temperature }\end{array}$ & $\begin{array}{c}\text { Added } \\
\text { Ampacity } \\
\text { compared } \\
\text { with no } \\
\text { adjustment } \\
\%\end{array}$ \\
\hline $40^{\circ} \mathrm{C}$ & $2198 \mathrm{Amps}$ & $17.8 \mathrm{~W} / \mathrm{m}$ & $+44 \%$ \\
\hline $50^{\circ} \mathrm{C}$ & $2213 \mathrm{Amps}$ & $23.7 \mathrm{~W} / \mathrm{m}$ & $+25 \%$ \\
\hline $60^{\circ} \mathrm{C}$ & $2228 \mathrm{Amps}$ & $29.44 \mathrm{~W} / \mathrm{m}$ & $+13 \%$ \\
\hline $70^{\circ} \mathrm{C}$ & $2320 \mathrm{Amps}$ & $35 \mathrm{~W} / \mathrm{m}$ & $+7 \%$ \\
\hline $80^{\circ} \mathrm{C}$ & $2334 \mathrm{Amps}$ & $40.9 \mathrm{~W} / \mathrm{m}$ & $+1 \%$ \\
\hline
\end{tabular}

Tables 1 and 2 show power line ampacity computation made for the same power line at the same environmental conditions; wind speed, ambient air temperature and rain. The only difference between the two tables is mathematical adjustment for rain is made in table 2 only. Where conductive heat flux exchange was integrated in the heat balance equation to cater for heat exchange between air and the conductor. This is 
different to the standard thermal computation equation in IEEE 738 standard (see table 1 above). As table 2 show, the existing framework does not offer any thermal allowance for cooling effect of rain.

In a previous study [14] it was proven experimentally that when it rains conductor temperature drops and thermal allowance of the conductor increases, their work involved heat application to a conductor to mimic thermal conditions that the conductor will see when in service. Heating was applied through cartridge heaters inserted on to the core of the conductor to ensure homogeneous distribution of heat throughout the conductor.

Magnitudes of these changes are dependent on so many factors such as type of air mass that carried the rain, ambient temperature, conductor temperature and most importantly wind speed. Nevertheless, it is possible to estimate ampacity with a high degree of accuracy equipped with the knowledge of weather forecast and conductor temperature alone. It is worth noting that the associated increase in wind speed that accompanies rain usually in the UK, which further helps reduce conductor temperature, was ignored for this study.

When tables 1 and 2 above are read in conjunction with Figure 1 - Thermal behaviour of AAAC conductor [below] compiled and collated by the author experimentally, the profound and fast effect of rain on thermal behaviour of bare power lines becomes apparent. Figure 1 below summarizes the steps and results of the experimental work.

- 7 minutes of rain application drops conductor temperature by $22^{\circ} \mathrm{C}$ from $77^{\circ} \mathrm{C}$ to $55^{\circ} \mathrm{C}$

- Then 3 minutes of rain application drops conductor temperature by $20^{\circ} \mathrm{C}$ from $73^{\circ} \mathrm{C}$ to $53^{\circ} \mathrm{C}$.

- When we adjust the computational equation for heat exchange facilitated by rain from air to conductor, we get about an added $+25 \%$ additional ampacity.

- The rate of temperature reduction when rain was applied for one minute was very Fast $\sim 53$ seconds, $\Delta \mathrm{T} \sim 13^{\circ} \mathrm{C}$.

- The rate of temperature increases when rain source was stopped was very slow $\sim 23$ minutes.

- Rain droplets alter the temperature of the air and this change in rate of temperature subsequently alters the ratio of air density to air viscosity in the air.

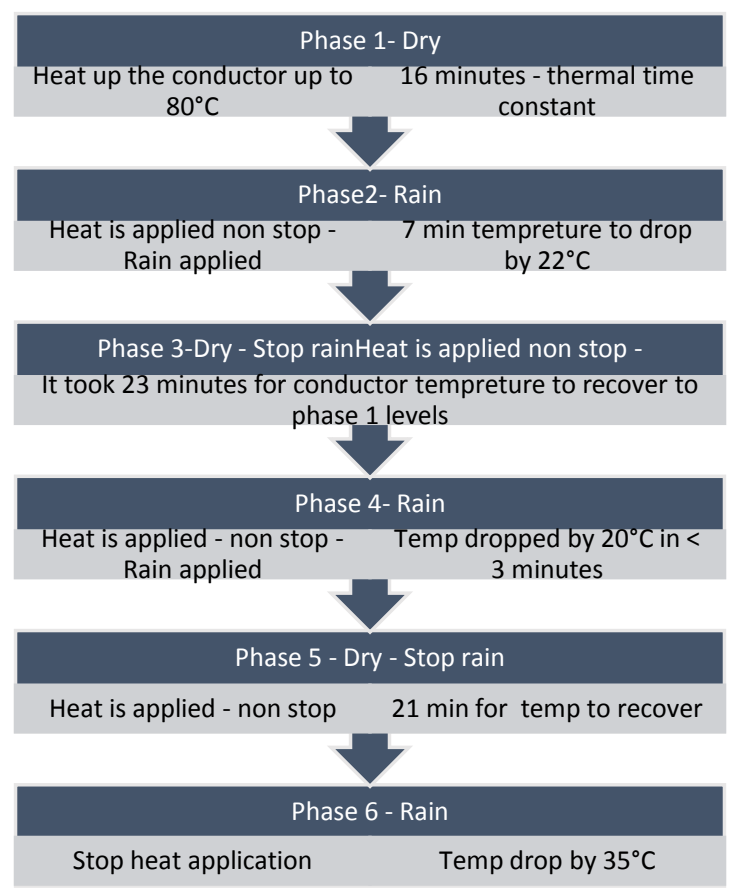

Fig 1-Thermal behaviour test sequence and behaviour of an AAAC conductor

\section{CONVECTIVE HEAT LOSS}

Convective cooling of aerial bare power conductors is accelerated during rain because rain increases air mass, which in turn reduces viscosity of air leading to a significant increase in thermal allowance of the power conductor. Researchers in [15] studied the impact of rain on power line's ampacity and outlined the effects increase in convective cooling during rain has on thermal rating of the line under rain, but equally detailed some limitations, such as need to consider impact of wind speed and requirement of specialist lab equipped with wind tunnels.

Empirical evidence gathered throughout the course of this study consistently show that during rain and regardless of any other weather conditions hot conductors cool down, the author applied rain at three different precipitation rates (18 $\mathrm{mm} /$ hour $-9 \mathrm{~mm} /$ hour $-2 \mathrm{~mm} /$ hour). While there were negligible differences on the results of the three applied rates, the effect of rain on conductor temperature at all rates was very fast and profound. This thermal behaviour is very important to transmission system operators as it help them compute available transfer capacity more accurately at a time when wind generation curtailment is becoming very common and widespread.

Table 3 - Computational comparative study -cooling parameters

\begin{tabular}{|c|c|c|c|}
\hline $\begin{array}{c}\text { Conductor surface } \\
\text { temperature }\end{array}$ & $\begin{array}{c}\text { Conductive } \\
\text { heat loss as \% } \\
\text { of the total } \\
\text { cooling }\end{array}$ & $\begin{array}{c}\text { Radiation } \\
\text { cooling as \% } \\
\text { of the total } \\
\text { cooling }\end{array}$ & $\begin{array}{c}\text { Convective } \\
\text { cooling as \% } \\
\text { of the total } \\
\text { cooling }\end{array}$ \\
\hline $50^{\circ} \mathrm{C}$ & $4 \%$ & $10.5 \%$ & $85.5 \%$ \\
\hline $60^{\circ} \mathrm{C}$ & $5 \%$ & $7.3 \%$ & $87.7 \%$ \\
\hline $70^{\circ} \mathrm{C}$ & $5.2 \%$ & $4.7 \%$ & 90.1 \\
\hline $80^{\circ} \mathrm{C}$ & $5.6 \%$ & $2.64 \%$ & $91.7 \%$ \\
\hline
\end{tabular}

Table 4 - Computational comparative study - cooling parameters

\begin{tabular}{|c|c|c|c|}
\hline $\begin{array}{c}\text { Conductor } \\
\text { surface } \\
\text { temperature }\end{array}$ & $\begin{array}{c}\text { Conductive } \\
\text { heat loss } \\
(\mathbf{W} / \mathbf{m})\end{array}$ & $\begin{array}{c}\text { Radiation } \\
\text { cooling } \\
(\mathbf{W} / \mathbf{m})\end{array}$ & $\begin{array}{c}\text { Convective } \\
\text { cooling }(\mathbf{W} / \mathbf{m})\end{array}$ \\
\hline $50^{\circ} \mathrm{C}$ & 14.4 & 39.5 & 323.1 \\
\hline $60^{\circ} \mathrm{C}$ & 20.2 & 32.0 & 387.7 \\
\hline $70^{\circ} \mathrm{C}$ & 25.9 & 23.86 & 452.3 \\
\hline $80^{\circ} \mathrm{C}$ & 31.7 & 14.9 & 517.0 \\
\hline
\end{tabular}

Tables 3 and 4 show a comparative computational study made to compare behaviour of all three heal losses in a hot 
conductor at different conductor surface temperatures. This helps in quantifying the magnitude of impact of each parameter in comparison to one another. It is apparent from computation in table above that convective heat transfer is the most effective parameter of all three. Authors of [16] suggest that convective heat loss coefficient can measured by measurement of the object's thermal time constant $\tau$. Experimental work conducted by the author in previous publication determined this as 15 minutes for an allaluminium alloy conductor AAAC Araucaria - cross sectional area 0.03726 meter.

\section{ECONOMIC AND SOCIAL IMPACT}

As the wind power generation is growing fast leading to increased pressure on existing transmission lines infrastructure and subsequently causing reduction in available transmission capacity and increased resultant generation curtailment. Some of social and economic impacts (list not comprehensive) are inefficient use of plots of land, discouragements of future wind power generation from investment and increase in connection of restricted wind farms offered no priority in dispatch and governed by manual or automated curtailment system [inter-trip]. This curtailment can be avoided by safely enhancing transmission lines ampacity, otherwise it will have grave economic consequences such as higher constraint cost payments being made as compensation to contracted wind farms. Higher MWh costs for available alternatives often running into 20 times + the cost of contracted generation. Two papers [17] [18] discussed the balancing challenges associated with generation management in a congested network like price risks, balancing risks and quantity risks normally associated with generation curtailment.

Price risk is a very credible risk because the main [back up] circuit protection employed in transmission lines in the United Kingdom are predominantly based on overcurrent protection $[\mathrm{O} / \mathrm{C}]$, the $\mathrm{O} / \mathrm{C}$ relays are set up to activate when certain current threshold is reached to trip out the relevant sections of the circuit. As majority of newly installed generation connections are wind farms these power outages happens at favourable wind generation conditions and favourable transmission lines cooling conditions restricting the ability of the system operator to use the available transmission infrastructure efficiently. System operator will then be pushed to re-dispatch power around the network and face the prospects of having to pay premium costs (sometimes running to $300 \%$ ) [19] to procure power from non-contracted generation plants.

The cascaded effect of current overload will also pose a balancing, quantity and congestion management risks that the system operator needs to consider. Impact of such as risks have two dimensions, first are financial in the form of constraint costs to contracted generation that will be restricted from generation. The second dimension; depending on where congestion occurred within the network, there will be a need to provide compensation to de-risk effects of curtailment and ensure required power quantity and quality supplied to end users are maintained at levels that meet grid code and other statutory regulations. The economic impacts of optimised line ratings on the German transmission system was analysed computationally by [20] who used the reduction of curtailment as a benchmark, a reduction of $15 \%$ was recorded. Another economic benefit of accurate ampacity computation is connecting two networks with different prices and balance mechanisms like generation and power distribution. A methodology proposed by [21] looked at enhancing the day ahead forecast using dynamic line rating because when weather forecast is known, maximum transfer capabilities can be easily computed with a "built in" relatively low margin of error. One of the reasons to build in a small margin of error into the computation is what [22] outlined about the difference wind attack angle in relation to the conductor can make to the computation results. Accurate ampacity computation of transmission lines has profound effect on reducing generation curtailment as it enables efficient utilisation of available transfer capability, maximizing value extracted out of transmission corridors in high wind profile areas.

\section{CONCLUSION}

As outlined above and since the heat loss side of the aerial bare power conductor's heat balance equation is very sensitive to precipitation. Because the magnitude and speed at which conductor's temperature change at is significant and long lasting enough to make it viable to enhance thermal ratings of line when rain is forecast. It is also worth noting that rate of convective heat loss doubles during rain, so does the conductive heat loss, albeit the increase in conductive heat loss is overshadowed by subsequent increase in convective heat loss, causing the total increase to be just $<2 \%$. However, this still causes the temperature of conductor to drop significantly adding instantly (taking all margins of errors into account- age of the conductor/ orientation / proximity of some spans to trees / physical condition/ oxidation) no less than $20^{\circ} \mathrm{C}$ to the overall thermal allowance of the conductor as shown in the empirical study above. This can be rounded up to about $15 \%$ increase in

ampacity of a power line before even looking at other metrological changes such as the increased wind speed and drop in ambient temperature phenomenon that usually accompany rain in the UK according to met-office. The author proposes to amend the ampacity computation framework in IEEE 738 heat balance equation to reflect these credible scenarios by integrating conductive heat loss and adding a multiplier to the convective heat loss transfer applicable only when rain is specified in weather forecast. In addition to the amended computation framework, the author highly recommends the installation of remote conductor temperature measurement devices on power lines that have historical evidence of congestion. Priority should be given to lines in areas of high historical precipitation rate and high 
wind speeds. In the United Kingdom transmission network, this area is the North West of Scotland.

\section{REFERENCES}

[1] Bishnu P. Bhattarai ; Jake P. Gentle ; Timothy McJunkin ; Porter J Hill; Kurt S. Myers ; Alexander W. Abboud ; Rodger Renwick ; David Hengst "Improvement of Transmission Line Ampacity Utilization by Weather-Based Dynamic Line Rating" IEEE Transactions on Power Delivery, 2018

[2] Standard for calculating current-temperature relationship of bare overhead conductors, IEEE738, 1993

[3] Bishnu P. Bhattarai , Member, IEEE, Jake P. Gentle, Senior Member, IEEE, Timothy McJunkin, Senior Member, IEEE, Porter J. Hill Member, IEEE, Kurt S. Myers, Member, IEEE, Alexander W. Abboud, Rodger Renwick, and David Hengst "Improvement of Transmission Line Ampacity Utilization by Weather-Based Dynamic Line Rating" IEEE Transactions on Power Delivery (Volume: 33, Issue: 4, Aug 2018)

[4] Svetlana Beryozkina, Antans Sauhats "Research and simulation of overhead power line uprating using advanced conductors" 2015 56th International Scientific Conference on Power and Electrical Engineering of Riga Technical University (RTUCON)

[5] Mostafa Nick ; Omid Alizadeh-Mousavi ; Rachid Cherkaoui ; Mario Paolone "Security Constrained Unit Commitment With Dynamic Thermal Line Rating "IEEE Transactions on Power Systems Year: 2016 Volume: 31 , Issue: 3

[6] Energy Networks Association "Engineering Recommendation P27: Current Rating Guide for High Voltage Overhead Lines Operating in the UK Distribution System" 1986.

[7] Judy Black; Stephen Connor; Jeremy Colandairaj "Planning network reinforcements with Dynamic Line Ratings for overhead transmission lines" 45th International Universities Power Engineering Conference UPEC2010

[8] Afzal, M., Gagnon, A. S. and Mansell, M. G. (2016) "The impact of the variability and periodicity of rainfall on surface water supply syst ems in Scotland". Journal of Water and Climate Change, 7 (2). pp. 321 339. ISSN 24089354

[9] M R Haylock et al., "A European Daily High-Resolution Gridded Data Set of Surface Temperature and Precipitation for 1950-2006," Journal of Geophysical Research 113, no. D20 (2008)

[10] Douglas Maraun, "When Will Trends in European Mean and Heavy Daily Precipitation Emerge?" Environmental Research Letters 8, no. 1 (March 1, 2013)

[11] M. Maksić ; G. Kosec ; V. Djurica ; A. Souvent ; R. Trobec "Dynamic thermal rating of power lines in raining conditions - model and measurements “ 2016 IEEE Power and Energy Society General Meeting (PESGM)" Year: 2016

[12] Murray W. Davis, "Nomographic Computation of the Ampacity Rating of Aerial Conductors" IEEE Transactions on Power Apparatus and Systems, 1970 , Volume PAS 83, issue 3

[13] Rosaria Conti, Aurelio Agliolo Gallitto, and Emilio Fiordilino, "Measurement of the Convective Heat-Transfer Coefficient" Online publication 11-May-2019

[14] J. G. Olazarri ; A. J. Mazon ; S. Rementeria ; I. Albizu ; E. Fernandez "Performance of dynamic line rating systems for wind integration " 2015 International Conference on Clean Electrical Power (ICCEP)

[15] G.W. Ault; K.R.W. Bell ; S.J. Galloway "Calculation of economic transmission connection capacity for wind power generation" IET Renewable Power Generation (Volume: 1, Issue: 1, March 2007)

[16] José Pablo Chaves-Avila; Fernando Banez-Chicharro ; Andrés Ramos "Impact of support schemes and market rules on renewable electricity generation and system operation: the Spanish case" IET Renewable Power Generation (Volume: 11 Issue: 3,222 2017)

[17] Balancing Mechanism - Elexon- National Grid - United Kingdom

[18] Bolun Xu ; Andreas Ulbig ; Göran Andersson "Impacts of dynamic line rating on power dispatch performance and grid integration of renewable energy sources" IEEE PES ISGT Europe 2013

[19] Romain Dupin ; Andrea Michiorri ; Georges Kariniotakis "Dynamic line rating day-ahead forecasts - Cost benefit based selection of the optimal quantile" CIRED workshop 2016 Finland.

[20] S. S. Girshin ; A. Ya. Bigun ; E. V. Petrova "Analysis of dynamic thermal rating of overhead power lines in the conditions of forced convection considering non-linearity of heat transfer processes " 2016 2nd International Conference on Industrial Engineering, Applications and Manufacturing (ICIEAM) 
